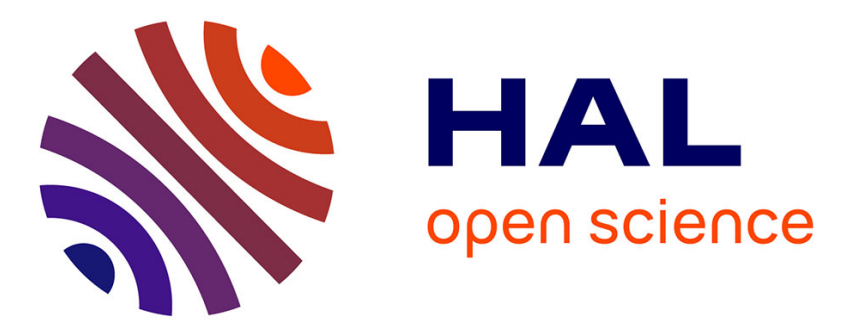

\title{
Identifying Learner's Engagement in Learning Games: a Qualitative Approach based on Learner's Traces of Interaction
}

\author{
Patrice Bouvier, Elise Lavoué, Karim Sehaba, Sébastien George
}

\section{To cite this version:}

Patrice Bouvier, Elise Lavoué, Karim Sehaba, Sébastien George. Identifying Learner's Engagement in Learning Games: a Qualitative Approach based on Learner's Traces of Interaction. 5th International Conference on Computer Supported Education (CSEDU 2013), May 2013, Aachen, Germany. pp.339350. hal-00854579

\author{
HAL Id: hal-00854579 \\ https://hal.science/hal-00854579
}

Submitted on 12 Mar 2015

HAL is a multi-disciplinary open access archive for the deposit and dissemination of scientific research documents, whether they are published or not. The documents may come from teaching and research institutions in France or abroad, or from public or private research centers.
L'archive ouverte pluridisciplinaire HAL, est destinée au dépôt et à la diffusion de documents scientifiques de niveau recherche, publiés ou non, émanant des établissements d'enseignement et de recherche français ou étrangers, des laboratoires publics ou privés. 


\title{
Identifying Learner's Engagement in Learning Games: a Qualitative Approach based on Learner's Traces of Interaction
}

\author{
Patrice Bouvier ${ }^{1,2}$, Élise Lavoué ${ }^{1,3}$, Karim Sehaba ${ }^{1,4}$ and Sébastien George ${ }^{1,5}$ \\ ${ }^{1}$ Université de Lyon, CNRS, \\ ${ }^{2}$ Université Lyon 1, LIRIS, UMR5205, F-69622, France \\ ${ }^{3}$ Université Lyon 3, MAGELLAN, LIRIS, UMR5205, France \\ ${ }^{4}$ Université Lyon 2, LIRIS, UMR5205, F-69676, France \\ ${ }^{5}$ INSA-Lyon, LIRIS, UMR5205, F-69621, France \\ \{patrice.bouvier, karim.sehaba\}@liris.cnrs.fr,elise.lavoue@univ-lyon3.fr, sebastien.george@insa-lyon.fr
}

Keywords: Game Based Learning: Learner Behaviour: Engagement Measurement: Qualitative Approach: Digital Gaming: Trace Theory.

\begin{abstract}
This paper proposes a qualitative approach for identifying learners' engagement from their traces of interactions performed in the learning game. Learners' engagement is an effective indicator of their motivation, acceptance and attachment to the learning activity. Engagement also informs about the relevance of the content and the effectiveness of the proposed interactive learning game. Designers, practitioners and teachers need information about engagement for analysing, designing and validating the learning game and also for modifying and adapting learning games in order to maintain their effectiveness. Currently, most of the approaches provide quantitative information about learner's engaged-behaviours. Thus, our objective is to extract qualitative information from learners-generated data. In this paper, we propose an approach in three stages that combines theoretical works on engagement and engaged-behaviours, Activity Theory and Trace Theory. By relying on traces of interactions, this approach enables to identify engaged-behaviours in low-constraint interactive games, directly, continuously, under ecological conditions and over a long time period. Then we present the results of a user study that demonstrate the feasibility and the validity of our approach. This study has been conducted on twelve traces composed of several thousands of learner-generated data.
\end{abstract}

\section{INTRODUCTION}

The features of digital games like multi-sensory immersion, interactivity and immediate feedback stimulate students' motivation and facilitate the development of skills like attention, problem-solving, decision-making or collaborative work (de Aguilera and Mendiz, 2003). Several studies (Gee, 2003; Egenfeldt-Nielsen, 2006) argue in favour of the use of digital games as efficient educational tools. This explains why computer supported education practitioners show a growing interest in digital game based learning (Prensky, 2007).

Student's engagement is considered as a useful indicator in order to prevent school dropout (Reschly and Christenson, 2006). Identifying engagement may inform about learners' motivation, acceptance and attachment to the learning mediated activity. It can also inform about the relevance of the content and the effectiveness of the proposed interactive technology or service. These information may be used by designers and teachers for testing, modifying or adapting the content or features of the system. During classroom lessons, teachers have the opportunities to assess and influence students' engagement (Skinner and Belmont, 1993) by adapting the form or the content of the lessons according to several students' characteristics such as personality, motivation, needs and affective states. With computer supported education, the relationship between teachers and students is limited, especially in the case of distance learning (Greenhow et al., 2009). Two means are available for eliciting and maintaining learners' engagement in mediated learning activities: either the mediated activity is intrinsically engaging (this is what is expected with the learning games), or the teacher has some information about learners' engagement.

In this paper, we propose an approach for identifying learners' engagement in learning games from their traces of interaction (i.e. learner's actions ac- 
tually performed within the mediated activity). This approach, useful for both teachers and designers, enables the direct and continuous analysis of students' engaged-behaviours under ecological conditions. We applied our approach through the analysis of 12 traces of interaction in a digital game.

This paper is organised as follow. In section 2 we refine the concept of engagement and review the methods for identifying it. In section 3 we describe the three stages of our qualitative approach. In section 4 we present the results of a user study and discuss them. Finally, in section 5, we conclude by showing the implications for computer-supported education and introduce some future works.

\section{BACKGROUND AND RELATED WORK}

In this section we study the notions of engagement. Our aim is to provide a definition that is applicable in both entertainment and learning fields. Based on this definition, we study the methods for identifying engagement in digital gaming.

\subsection{Defining Engagement in Digital Gaming}

(Boyle et al., 2012) observe in their systematic review on engagement in digital games, that the nature of engagement is still not well understood and that there is still a lack of a widely accepted definition of engagement. Defining an abstract concept like engagement is useful in order to facilitate scientific exchanges, especially when the concept is used in several fields. Also, it helps to be clear about what is aimed, or what is being measured. Thus, it improves the validity and effectiveness of the comparisons between several methods or approaches. (Brown and Cairns, 2004) define engagement as "the lowest level of immersion" before "engrossment" and "total immersion". (Brockmyer et al., 2009) consider engagement "as a generic indicator of game involvement" which can evolve on a progressive scale whose levels are immersion (Jennett et al., 2008), presence (Tamborini and Skalski, 2006), flow (Csikszentmihalyi, 1991) and psychological absorption (total engagement).

In the field of education, engagement may be considered as the "behavioral intensity and emotional quality of a person's active involvement during a task" (Reeve et al., 2004). After reviewing the concept of school engagement, (Fredricks et al., 2004) conclude that engagement is a "meta con- struct" which encompasses "behavioral" (participation, positive conduct, effort), "emotional" (interest, positive emotions) and "cognitive" (psychological involvement in learning, self-regulation) dimensions.

The first issue with these definitions is the reference to ambiguous concepts like involvement and immersion. The second issue is that these definitions are context-dependent (for example the definitions in the entertainment field seem to address more specifically the immersive games). As we aim to provide a definition that is valid in the both fields, we think more relevant to answer through a conceptual definition that focuses on the state of engagement rather than to its outcomes.

So we consider engagement as "the willingness to have emotions, affect and thoughts directed towards and determined by the mediated activity". Engagement occurs if players or learners' expectations (perceptual, intellectual, interactional) are fulfilled. Then, in a process similar to the suspension of disbelief $^{1}$ (Coleridge, 1969) players and learners may willing to get engaged in order to live more intensely the activity. Then they accept that, during a given time (perhaps beyond the duration of the mediated activity), their emotions, affect and thoughts will be mainly elicited by the mediated activity (here the digital game-based learning). The consequence of this engaged state, is that players' or learners' attention will remain on the game and their motivation will make them keep playing and coming back (again and again) in the game.

\subsection{Identifying Engagement in Digital Gaming}

Our objective is to analyse learner's engagement directly (i.e. from their actions and not a posteriori), continuously and over a long time period (i.e. session after session across weeks and months) and under ecological conditions (i.e. at home and without interfering with the learner's activity nor impacting the system). Our approach must allow to analyse the whole population of users rather than a selected sample and must be effective with interactive systems that offer a wide range of actions. Therefore, we do not address in this section psychophysiological or self-report, interview and observation methods (see respectively (Kivikangas et al., 2011) and (Fredricks and McColskey, 2012) for recent reviews).

Metrics approaches are used in industry and academics for meeting the previously mentioned con-

\footnotetext{
${ }^{1}$ Suspension of disbelief is the willingness to accept, despite the technical or narrative shortcomings, a fictional work as being the reality.
} 
straints. It consists in automatically collecting and storing any users' actions performed through input devices towards the system such as, users' choices, location changes, modifying character's characteristics, interaction with other character but also information like time spent or the level reached. Thus, it is possible to record all the users' course and process during the activity. Then, some data mining methods can be applied on these user-generated data in order to derive valuable (i.e. interesting, interpretable and useful) information. See (Romero and Ventura, 2010) for a review addressing specifically learner-generated data. As metrics only inform on what users are doing but not why, one may see a limit in aiming to identify engagement (i.e. an abstract quantity) from metrics (Canossa and Drachen, 2009).

As engagement influences the behaviour, some measurable quantities can be considered for identifying engaged-behaviours (Bauckhage et al., 2012). For studying the impact of tutorials on players' engagement in digital entertainment games, (Andersen et al., 2012) collect some raw data like the number of unique levels completed, the total playing time and the number of times players have loaded the game. Expecting to predict when players will stop playing, (Bauckhage et al., 2012) study how engagement evolves over time. They apply techniques from lifetime analysis on player's playing times information (when they play and for how long) collected from five AAA-games like Tomb Raider or Crysis. (Weber et al., 2011) study players' engagement in terms of player retention within an American football game. For that purpose they collect preference data such as the game mode selected and behavioural data like average yards gained or ratio of possession. Dealing with learner's disengagement detection in web-based e-learning system, (Cocea and Weibelzahl, 2009) compare eight machine learning techniques on several raw data. The latter are mainly related to reading pages (number of pages read, time spent reading pages) and quizzes events. The previous methods conduct quantitative measure on isolated (i.e. unlinked) data item. Thus, rather than addressing engaged-behaviour as a whole, they stay at a basic level by only considering some parts of an engaged-behaviour.

Some approaches are considering user's engagedbehaviour through some sequences of actions. (Beal et al., 2006) propose a classification approach of learner's engagement within a mathematics ITS. For that purpose, they defined five student's timedependent patterns of actions based on time traces of actions within the ITS. More recently, (Köck and Paramythis, 2011) adopt a clustering approach for detecting sequences of learner's actions in the Andes
ITS. These studies only occur in high-constraint environment like ITS. In such environments, the variety of actions is tight and fully determined by the interactive system (attempts, request for hint, results etc.). In this case the number of items is limited. Thus, sequencemining may constitute an efficient method for discovering some statistically relevant sequences of actions. But, in low-constrained interactive systems like learning game, a wide range of actions may be possible. Then, sequence-mining could return a too large number of sequences. Also, as the temporal succession of actions does no imply that there is a coherence between these actions, these actions may be not useful in order to derive valuable information about a high-level engaged-behaviour. Moreover, machine learning for sequential data mining suffers from several issues like long-distance interactions (Dietterich, 2002). This can be problematic if, within an engagedbehaviour, a long period occurs between items.

\section{AN APPROACH FOR IDENTIFYING ENGAGED-BEHAVIOURS}

In this section we present our qualitative approach for analysing directly, continuously and under ecological conditions learner's engaged-behaviours in lowconstraint interactive games and over a long time period. For that purpose we consider learner's behaviour as a chain of actions actually performed in the digital game. A chain of actions is an aggregation of learner's actions selected from temporal constraints and/or characteristics of the action. By aggregating several actions, we expect a comprehensive contextual information about learner's engagement. Also we adopt a theory-driven perspective by firstly determining some engaged-behaviours. Therefore, the challenge is to identify, among the wide variety of possible actions, those that are inherent to the engagement. These actions can refer to a high number of dimensions of the interactive systems and be collected at different granularity of temporal and spatial resolution. So, three main issues have to be overcome:

1. Determining some high-level engagedbehaviours.

2. Characterising these engaged-behaviours by identifying the underlying chains of actions.

3. Detecting these chains of actions among all the actions recorded.

Our strategy for tackling these three issues is in three stages. Each stage is described in the following three sub-sections. 


\subsection{Determining Engaged-Behaviours}

In this section we describe how we determine some high-level engaged-behaviours. To decide whether a behaviour reflects, or not, an engagement, we consider the question of the learners' motives and needs that determine engagement. This is useful in order to give meaning, in relation to their engagement, to users' actions.

(Przybylski et al., 2010) use the SelfDetermination Theory (SDT) (Ryan and Deci, 2000) for explaining digital game engagement. The SDT identifies three basic psychological needs: competence (sense of efficacy), autonomy (volition and personal agency) and relatedness (social interaction). This perspective is different from other works based on empirical observations on players' behaviours. (Lazzaro, 2004) identifies four motivational factors for playing game labelled hard fun (challenge), easy fun (curiosity, fantasy), altered state (positive emotions) and people factor (social experiences). (Yee, 2006) observes three main components: achievement, social and immersion.

Even if these motivational factors are closed to the basic psychological needs previously mentioned. The basic psychological needs perspective has several advantages. As it is not based on empirical observation of players' behaviours on specific games, it does not depend on the gameplay ${ }^{2}$ of the game. Thus, basic psychological needs perspective can be applied on all current or future gameplay. By being more versatile, this approach enables to determine a wide and nonstereotyped range of behaviours. Our aim is neither to determine a user model nor to provide a model of engagement but to identify some behaviours that significantly reflect learner's engagement (i.e. that are not determined by the gameplay of the learning game). Thus, for qualifying a behaviour of being engaged, we link users' behaviours to the universal needs identified by the SDT that they satisfied.

For structuring the analysis of engagedbehaviours, we consider that digital gaming consists in performing some actions (decision-making process), directly or through a character, within an environment (or at least on a frame) which may involve social interaction with human or virtual agents. Thus, the gaming activity has the following four dimensions: environmental (in relation with the $a u$ tonomy need), social (in relation with the relatedness need), self (in relation with the autonomy need) and action (in relation with the competence and autonomy

\footnotetext{
${ }^{2}$ In digital gaming, gameplay is a blanket term which refers to the structure, the dynamics or the interactive aspects of a game.
}

needs). Of course, according to the type of learning game (simulation game, computer supported collaborative learning), the components will not always be present, nor with the same intensity. Each component encompasses several engaged-behaviours including those observed by (Lazzaro, 2004) and (Yee, 2006). See Table 1 for an overall summary of the four components of players engagement.

\subsubsection{Environmental Engagement}

Player's engagement is directed towards the environment or the world depicted in the game. This engagement encompasses two main behaviours: the contemplation and the curiosity. Contemplatives like to stroll in the game area. Curious seek to know the physical and geographical boundaries of the game world. They may also be interested in configuring the features of the game. The goal is not to win but to increase their knowledge about the game.

\subsubsection{Social Engagement}

Social engagement refers to the social connections within the game. In this case, the game is an opportunity to create and expand social relations toward other players. The purpose is to develop and/or to maintain her/his social network. This player will massively use the communication channels provided, will promote the game to increase the number of participants, will enjoy teamwork (collaborative work in a serious game, within a team or guild in a digital game).

\subsubsection{Self Engagement}

Self engagement concerns the connection between players and their character through identification and/or ownership aspects. These players like to customize their avatar and choose accessories for some other reasons than performance. Players experiencing this type of engagement will be particularly involved in shopping stage (for a new sword, costume, skills etc.). Thus, they may spend a long time to study the characteristics of accessories or skills. This player will take care about the role play.

\subsubsection{Action Engagement}

Player's engagement is directed towards the actions to perform in the situation depicted by the game. The core of the game is the main interest for these players. Players will try to quickly pass the levels, to win experience points, to complete challenge etc. 
Table 1: Categorisation of (non-exhaustive) players' behaviours through the four components of engagement and some associated activities.

\begin{tabular}{|c|c|c|c|c|}
\hline & $\begin{array}{l}\text { Environmental en- } \\
\text { gagement }\end{array}$ & Social engagement & Self engagement & Action engagement \\
\hline $\begin{array}{l}\text { Learner's } \\
\text { behaviours }\end{array}$ & $\begin{array}{l}\text { Contemplative } \\
\text { Curious }\end{array}$ & $\begin{array}{l}\text { Collaboration } \\
\text { Competition } \\
\text { Social relatedness }\end{array}$ & Managing an avatar & $\begin{array}{l}\text { Surpassing oneself } \\
\text { Enhancing skills }\end{array}$ \\
\hline Activities & $\begin{array}{l}\text { Virtual trip } \\
\text { Trying to reach the } \\
\text { limit of the game } \\
\text { Discovering extra- } \\
\text { content }\end{array}$ & $\begin{array}{l}\text { Expanding social } \\
\text { network } \\
\text { Liven up the group } \\
\text { of real friends } \\
\text { Enjoyment with } \\
\text { others }\end{array}$ & $\begin{array}{l}\text { Customizing the } \\
\text { character } \\
\text { Developing a } \\
\text { story around the } \\
\text { character }\end{array}$ & $\begin{array}{l}\text { Be a top scorer } \\
\text { Completing chal- } \\
\text { lenges }\end{array}$ \\
\hline
\end{tabular}

\subsection{Characterising Engaged-Behaviours}

The previous section on engagement enables to determine some engaged-behaviours by establishing the relationships between needs, motives and engagedbehaviours. This section describes how we characterise these engaged-behaviours. By characterising an engaged-behaviour we mean identifying the underlying actions and chains of actions performed by the learner within the learning game. Our aim is to select, among the various dimensions of the game, the relevant user-generated data i.e. the ones underpinning an engaged-behaviour. To reach this objective, we base on the Activity Theory to establish the relationship between the learners' needs, the object and motive of the activity and the actual realization of actions.

\subsubsection{Basic Concepts of Activity Theory}

Activity Theory (Vygotsky, 1978; Leontiev, 1978) aims to understand Human development through an analysis of the "genesis, structure and processes of their activities" (Kaptelinin and Nardi, 2006). Three different levels of analysis of the activity are distinguished :

- Activity An activity is performed by a subject, through a tool, in response to a specific need or motive in order to achieve an object (objective). The need generates the motive, the motive elicits the activity, the object structures and directs (Kaptelinin, 2005) the activity towards a desired and anticipated (Bardram, 1997) outcome. Object is what characterises an activity and differentiates an activity from another (Leontiev, 1978). The object has to be of high significance i.e. be self-sufficient.

- Action An action (or chains of actions) can be seen as the actual transcription of the activity. An action can be used by different activities in or- der to reach a goal. Thus, the goal of the action depends on the activity to which it is subordinated. The difference between objects (activity level) and goals (action level) is the significance. Actions are performed consciously and with effort through operations.

- Operation An operation enables the actual realisation of the actions. Operations are automatized, that means performed without conscious thoughts or efforts. Operations are determined by the environmental and contextual conditions of the activity. Operations can be used by different actions.

\subsubsection{Characterising Engaged-Behaviours with Activity Theory}

We use Activity Theory as a hierarchical framework for conducting a comprehensive and structured analysis of the engaged-behaviours within the learning game. This structuring tool enables to deconstruct an engaged-behaviour in activity, chains of actions and chains of operations actually performed in the interactive learning game by the students. So, within each components of engagement, activities share the same motive but have a different object. For example, the activities "Expanding social network" and "Liven up the Group of Friends" share the same motive (Feeling emotions related to social interactions) which is generated by the relatedness basic need but have different objects (respectively Increasing the number of Friends and Maintaining a group activity within the Group). In this, we comply with Kaptelinin's call (Kaptelinin, 2005) by distinguishing between $o b$ ject and motive of the activity.

Let's consider an example (illustrated on Figure 1) extracted from the user study presented in section 4 . In the social engagement component we identify the activity : Expanding social network whose motive is Feeling emotions related to social interactions and object is Increasing the number of Friends. In our 


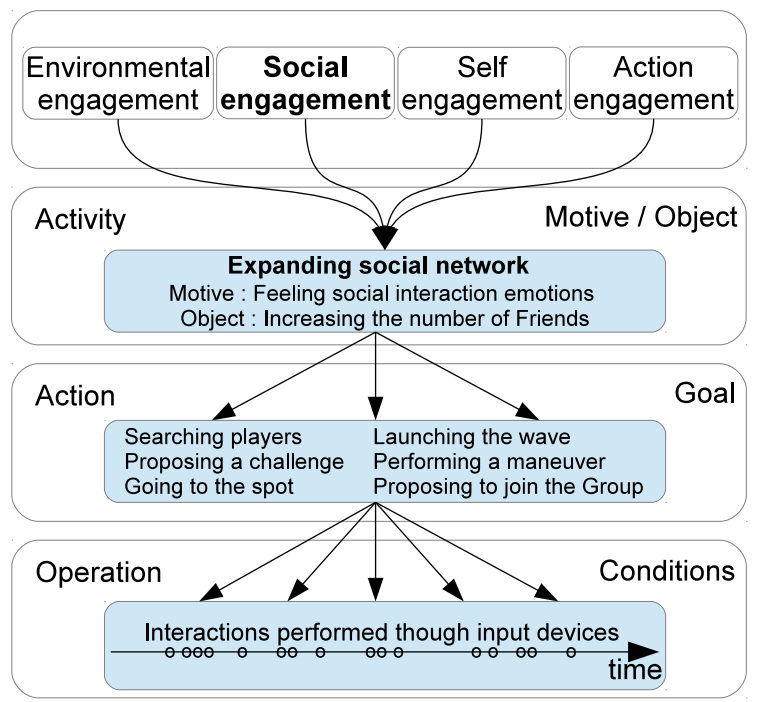

Figure 1: Social engagement in conjunction with Activity Theory hierarchy within the user study presented in section 4 .

study this activity is deconstructed (i.e. supported) by the following actions:

- Searching players living in a specific location

- Proposing a challenge to another player

- Going to the spot

- Launching the wave

- Performing a maneuver

- Proposing to join the Group of Friends

All these actions are realised in the game through many operations actually performed with the input devices provided. These operations can consist in some mouse clicks or forms filling like for example typing the name of a town in the form for searching players or a button-pressed for launching a wave.

\subsection{Detecting Engaged-Behaviours}

In section 3.1 we determine some engagedbehaviours. In section 3.2 we characterise these engaged-behaviours by deconstructing them in activities, actions and operations. This section describes the last stage of our qualitative approach based on the Trace Theory. The objective here is twofold. First we detect within the recorded learner-generated data the chains of operations identified in the previous stage. Then, we reify the relationship between operations, actions and activities. The objective is to extract the identified activities from the raw learner-generated data.

\subsubsection{Concepts of Trace Theory}

The trace analysis approach is a framework for collecting, organizing and using user's activity traces (i.e. any player's actions performed towards the learning game) (Clauzel et al., 2011). At the lowest level, there is the observed elements (labelled obsels). Typically, an obsel corresponds to a player's raw action collected in the game (like a mouse click or a key pressed on the keyboard). An obsel contains a type of event, a timestamp and a set of contextual information useful for characterising the event and to derive meaning. A primary trace is a set of obsels temporally situated which may be connected. A primary trace may contain a very large number of obsels whose informational level may be too low. So, it may be difficult to derive knowledge from a primary trace.

The formalization proposed by (Settouti et al., 2009) aims to facilitate the transition from primary traces to information that makes sense. This formalization uses a model of trace in order to organise and characterise the obsels within the trace. This model defines the types of the obsels and the types of the relation that compose the trace. It also considers a model of transformation which is a set of rules whose role is to transform a trace in a transformed trace of a higher level. A rule consists in temporal constraints or in operations on the contextual attributes performed between obsels. The transformed traces help to derive a more complex or abstract knowledge.

\subsubsection{Detecting Engaged-Behaviours with Trace Theory}

We use the Trace Theory for addressing the third issue: detecting the engaged-behaviours among all the actions recorded. We combine Activity Theory and Trace Theory by establishing the following correspondences between these two theories:

- operation $\Leftrightarrow$ primary trace composed of obsels

- action $\Leftrightarrow$ primary transformed trace

- activity $\Leftrightarrow$ highest-level transformed trace

Trace Theory enables to detect the relevant operations among all the stored obsels and then to reify (through the transformation process) the relationship between operation, action and activity. The obsels which compose the highest-level trace correspond to the activities that belong to a specific engagedbehaviour.

Lets consider an example illustrated by the Figure 2. During a session we collect many obsels from several types (i.e. which correspond to specific events such as asking another player to become friend, 


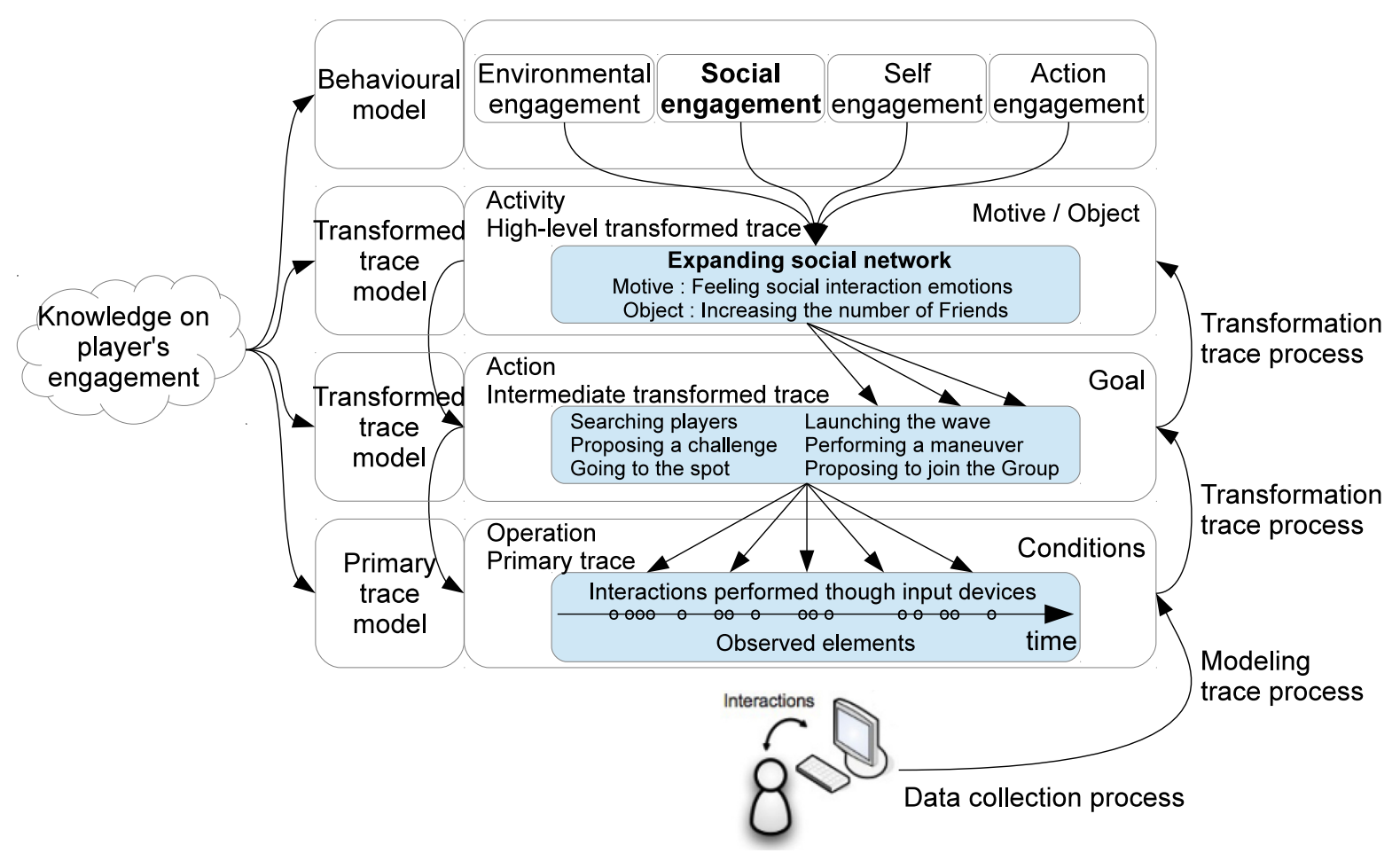

Figure 2: Our approach combines a theoretical work on engagement and engaged-behaviour, Activity Theory and Trace Theory for identifying engaged-behaviours from traces of interaction. An example extracts from the user study presented in section 4.

launching a wave etc.). We define a model of primary trace in order to organise and characterise the obsels within the primary trace. Then we also define a transformation model. In the latter we create a rule labelled "Searching players by town" (see section 4.2.2 for an example of rule). This rule enables to detect in the primary trace, according to some temporal constraints, the presence of the pair of obsels "open the social search form" and "filling the players' town form". If they occurred within a certain time interval then the transformation rule generates a new obsel of higher-level (labelled "Searching players living in a specific town") in a new transformed trace. The transformation model has also a rule labelled "Proposing a challenge" and so on. A second transformation model loads the previously generated transformed trace in order to generate the highestlevel transformed trace. The latter may contain the obsel of highest-level that corresponds to the activity "Expanding social network".

\section{USER STUDY}

The objective of our study is twofold. We want to verify (1) the feasibility of the whole process (i.e. col- lecting the user-generated data and determining, characterising and detecting some engaged-behaviours) and (2) the validity of our approach i.e. do the behaviours we detect reflect an engaged-behaviour?

We apply our approach on an online game. This game enables to work on a base of 150000 active players per month and so on 150000 traces. Also, this game enables to analyse engaged-behaviours in lowconstraint interactive systems, directly, continuously and under ecological conditions and over a long time period. And finally the social and challenge dimensions are strong enough for providing a wide variety of engaged-behaviours. We first present the context of our user study. Then we detail the whole process for identifying some engaged-behaviours and present some results.

\subsection{Context}

For this research, we rely on the games developed by the company IntellySurf under the label YouRiding $^{3}$. We consider the YouRiding Bodyboarding games which take advantage of the Unity ${ }^{4}$ game engine. The Bodyboarding game consists in travelling

\footnotetext{
${ }^{3}$ YouRiding: http://www.youriding.com

${ }^{4}$ Unity - Game Engine: http://unity3d.com
} 
Table 2: Deconstruction of the activity Completing challenges in actions and operations. The activity Completing challenges is supported by the chain of actions To obtain information about the challenge - To improve the equipment To improve the rider skills. The action To obtain information about the challenge is detecting through the operations game_open_profile_improvements and game_open_profile_skills.

\begin{tabular}{|l|l|l|l|l|}
\hline Activity & \multicolumn{4}{|c|}{ Completing challenges } \\
\hline Actions & $\begin{array}{l}\text { Obtaining information } \\
\text { about the challenge }\end{array}$ & $\begin{array}{l}\text { Improving the charac- } \\
\text { ter's equipment }\end{array}$ & $\begin{array}{l}\text { Improving the charac- } \\
\text { ter's skills }\end{array}$ & $\begin{array}{l}\text { Paying for new } \\
\text { credits }\end{array}$ \\
\hline Operations & $\begin{array}{l}\text { open_profile_improvements } \\
\text { open_profile_skills }\end{array}$ & $\begin{array}{l}\text { open_shop } \\
\text { shop_buy_item } \\
\text { shop_buy_with_cash } \\
\text { open_profile_quiver } \\
\text { item_equip } \\
\text { item_repair }\end{array}$ & $\begin{array}{l}\text { open_tricks } \\
\text { open_key_config }\end{array}$ & process_bank \\
& & & \\
\hline
\end{tabular}

from spot to spot all over the world in order to select the most effective waves for performing some maneuvers (like tube ride), completing a challenge or challenging other players. Players have to detect when their character reaches the best zone of the wave to perform a maneuver (lip or tube of the wave etc.) with the right key combination. Players must also adopt the right strategy for trying only maneuvers that their character's skills and equipment can perform. Players should also make the right choices concerning the improvements of character's skill and equipment.

\subsection{Implementation of our approach}

In this section we describe the implementation of our qualitative approach in the game used for the user study. We first show how we determine and characterise some engaged-behaviours. Then we explain how we detect these engaged-behaviours among all the interactions recorded.

\subsubsection{Determination and Characterisation of Engaged-Behaviours}

This is the theory-driven part of the process for identifying some engaged-behaviours. In this example we consider the engaged-behaviour Completing challenges. The latter belongs to the Action Engagement component presented in section 3.1.4.

Then we characterise this engaged-behaviour through an Activity Theory perspective (see section 3.2.2). The table 2 details all the elements of this deconstruction. The analysis indicate that the activity Completing challenges is supported by the actions Obtaining information about the challenge - Improving the character's equipment - Improving the character's skills. A fourth action Paying for new credits is an option. Indeed, some players may buy some credits for improving their rider's equipment or skills. The action Obtaining information about the challenge is realized through the operations open_profile_improvements and open_profile_skills. These two operations indicate that the player has open the two pages that inform about the different challenges to complete.

\subsubsection{Detection of Engaged-Behaviours from the Traces of Interaction}

We collect 89 types obsels (i.e. raw user-generated data raw) such as fb_link_account (a player connect her/his facebook account whith her/his account in the game), challenge_wait (a player propose a challenge) or goto_spot (a player go to a specific spot identified with its id) etc. The collect uses a classic client-server architecture with JavaScript and PHP scripts. The collect is automatically triggered when the player performs a targeted action (typically a click). The obsel is then sent to a server for being stored, session after session, in a MySQL database.

We use the tool D3KODE ${ }^{5}$ (Champalle et al., 2012) for analysing the traces and defining the transformation rules (see section 3.3.1 on the Trace Theory). D3KODE provides the following features: loading the data as a primary trace, creating the models of transformation and the rules associated and a graphical visualization of the (primary and transformed) traces (see Figure 3 for an illustration). So, the data are exported from the MySQL database in a CVS (Comma-Separated Values) file that is compatible with D3KODE. Each line of this file contains two timestamps (the date and time of the beginning and end of the event, most of the time it's the same value), the name of the obsel and at most three attributes which may provide some contextual information such as the name of the button pressed, the identification number of the spot or of the equipment etc.

\footnotetext{
${ }^{5}$ Define, Discover, and Disseminate Knowledge from Observation to Develop Expertise
} 
Then we load the CVS file in D3KODE in order to obtain a primary trace.

In order to visualise the action level we apply a transformation to the primary trace. This transformation is a set of rules that enables to aggregate several operations in order to generate a high-level obsel. A rule can rely on temporal constraints or on the contextual attributes. This high-level obsel corresponds to an action. For example the obsel open_profile_improvements and open_profile_skills are aggregated in order to generate the action Obtaining information about the challenge. The following rule enables to select the instances where the two pages Improvements and Skill have been opened during an interval of 2 minutes. The analysis of several traces of interaction indicates that players consult these two pages in this interval.

11

2 open_profile_skills.hasEnd < open_ profile_improvements.hasBegin

3 (open_profile_improvements.hasBegin - open_profile_skills.hasEnd) $<=120$

4

$5 \mathrm{OR}$

61

7 open_profile_improvements.hasend < open_profile_skills.hasBegin

8 (open_profile_skills.hasBegin open_profile_improvements.hasend ) $<=120$ )

9

We observe that the action Obtaining information about the challenge occurs many time for some players in their whole traces and never for other players. In a similar manner we create all the rules that enable to generate the four actions. And we iterate the transformation process for aggregating the actions and then generating the obsel of highest-level (i.e. the one that indicates the activity Completing challenges). In this case the temporal constraint may be larger as for example the action Improving the rider's equipment occurs less often than the action Obtaining information about the challenge .

\subsection{Results}

We collected twelve player's traces on the period from January to April 2012. These traces from engagedplayers have been isolated by experts. A trace contains 89 types of obsels and can be composed of several thousands of obsels. We are able to detect $20 a c$ tions such as Promoting the game towards facebook,
Being interested in other players' information, Improving the equipment, Paying for new credits etc. We identify six activities from the four components of engagement such as Expanding social network, Animate facebook group of friends, Completing challenges etc. These results show the feasibility of the whole process. This process is illustrated in Figure 3.

We also observe that the players who play the most (the sessions of play are spread over the whole period of four months) show several activities from several components of engagement. On the contrary, players who stop playing after only several sessions of play (typically spread on only one month) show no activities. This confirms that the behaviours we detect reflect an engagement. Also it seems to indicate that the variety of the performed activities is a relevant information regarding the engagement.

\subsection{Discussion}

Compared with a quantitative approach that would have done some statistical measures on the number of waves surfed by the player, our qualitative approach go beyond this information by identifying in which chains of actions a wave has been surfed. Indeed, we know if a wave has been surfed in order to complete a challenge or for challenging another player in order to be introduced with her/him.

For this user study we worked on twelve traces for implementing the transformation rules. The rules can be used on other players' traces of interaction from the game studied in this paper. Also theses rules could be applied to other digital games. From the designer point of view, the adaptability to various game engines would be fairly simple as few lines in JavaScript are needed in order to trigger the sending of an event. The activities and actions level, and the rules allowing to infer activities from actions are broadly shared by different types of games. For example, the action Challenging another player has the same meaning as soon as there is a confrontation between learners. But, the operations are determined by the design and interface of each game. Therefore, only the operations level and the rules allowing to infer actions from operations depend on the game. Also, the scalability (number of players, volume of collected data) comes to the Big Data issue. Thus, two points may be improved: the asynchronous transmission (but features of html5 such as WebSockets will facilitate it) and the storage (NoSQL databases are a promising solution).

We already have done some preliminary comparisons with a sequence-mining algorithm. In the traces we analysed, the four obsels goto_map, goto_zone, goto_spot and play_start_on_spot represent more than 


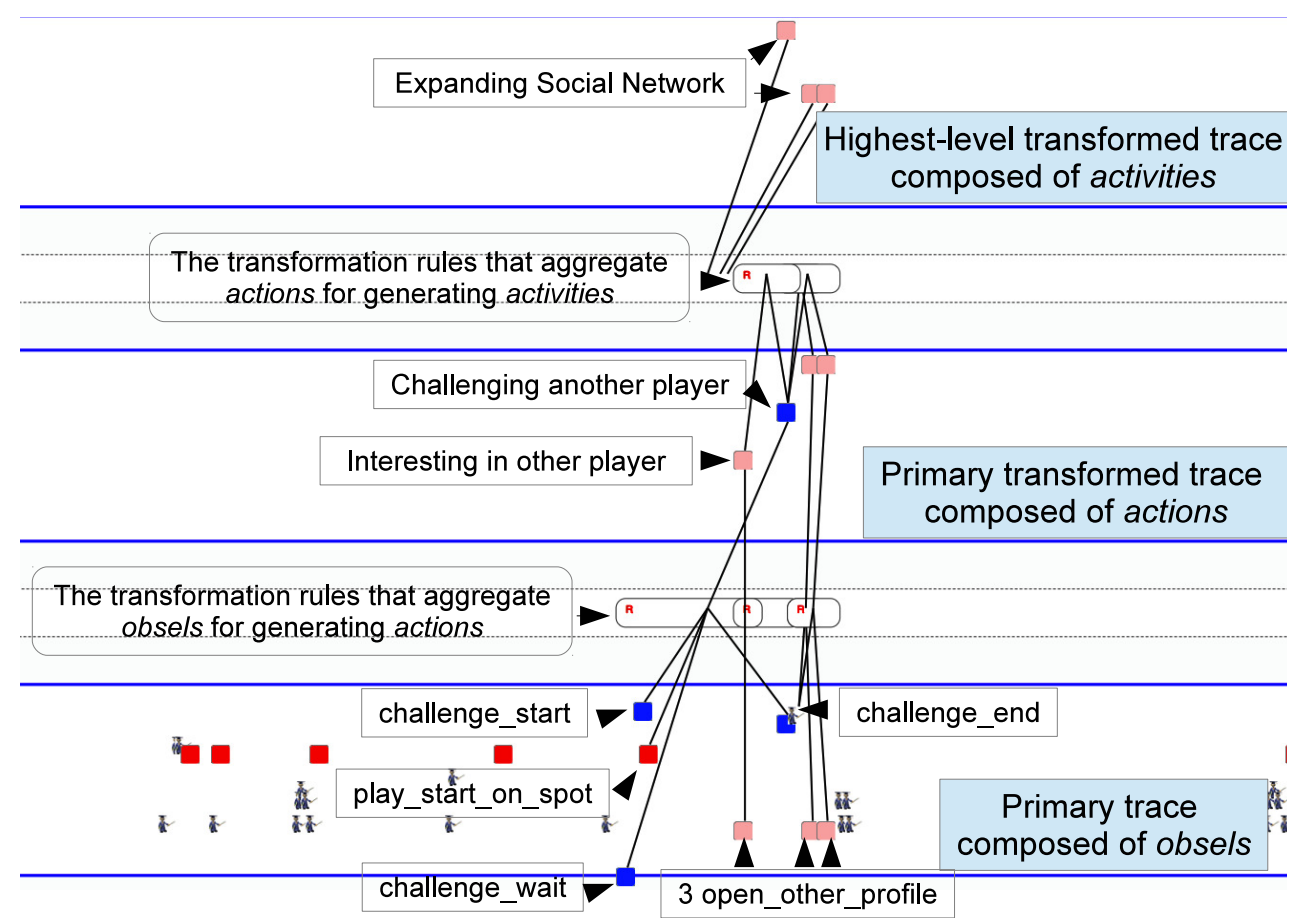

Figure 3: Graphical visualisation in D3KODE of the tranformation process from the obsels to a high-level engaged-behaviour.

the half of the obsels that compose a player's trace. The results obtained with this algorithm mainly refer to sequences combining these operations. These are what we call trivial sequences are they are fully determined by the gameplay of the game. These results seem to confirm the validity and effectiveness of our approach compared to sequences mining methods. This may be particularly true when the variety of actions within the interactive system is wide.

\section{CONCLUSION AND FUTURE WORK}

\subsection{Summary of the Contribution}

We propose a theory-driven and qualitative approach for identifying engagement from users' traces of interaction. This approach enables to identify engagedbehaviours in low-constraint interactive systems, directly, continuously and under ecological conditions and over a long time period.

For using qualitatively, rather than quantitatively, learners-generated data, we propose an approach in three stages: (1) determination of high-level engagedbehaviours, (2) deconstruction, from an Activity Theory perspective, of these engaged-behaviours in $a c$ tivities, actions and operations, (3) detection of the chains of actions among all the stored learnergenerated data based on Trace Theory in order to extract the engaged-behaviours.

We present the results of our user study on twelve traces of interactions in order to demonstrate the feasibility of the whole process and to validate the approach.

\subsection{Implications}

Besides the psychological, physical, cognitive, social and cultural learner's factor, the effectiveness of the learning game depends on two categories of factors: the immersive and interactive features and the content (consistency and authenticity, narrative process, aesthetics) (Dondlinger, 2007). Our approach provides a structured tool for analysing the actual use of the game. The results may be different from designers' intuitions. It may also inform about what players want, what is missing in the game (like a wrong balance between the components of engagement). Thus, designers may modify the game in order to improve the player's experience.

Moreover, the process of engagement (Brien and Toms, 2008) (point of engagement, engagement, disengagement, reengagement) enables to deal with the aspect of temporality, i.e. how engagement evolves over time. Thus, the identification of learner's engagement during several sessions may be a useful in- 
formation for teachers for maintaining engagement by adapting the content or the form of the learning activity. Also this information could be directly used by the interactive system for an automatic adaptation or for giving a feedback to learners.

We consider that engagement might be a concept easier to grasp and to identify than the user experience $^{6}$ in learning game. Thus, engagement and our approach for identifying it might provide a relevant information for designers, practitioners and teachers for analysing, designing and validating the learning game but also for modifying and adapting it in order to maintain the effectiveness of the learning games.

Also, our approach is not limited to immersive games like the one used for our user study. Indeed, our approach can be applied as soon as learners have some choices to perform (and thus there is some chains of action to analyse). Finally, this approach is not limited to engaged-behaviours and can be applied for identifying any evolution of behaviour from any type.

\subsection{Future Works}

Our approach is currently carrying out a posteriori and manually. But by conducting a regression analysis on players' actions, it could be possible to detect and then to select the most relevant (i.e. the most discriminant) activities and actions. Thus, by reducing the complexity of the calculations, it may be possible to automatise the method in order to identify engagement in real-time (i.e. during the mediated activity). The next step would be the automatic adaptation of the system to elicit and to maintain the engagement.

We plan to conduct a concurrent triangulation mixed-method by comparing and contrasting our results with subjective method like questionnaire or interview applied to "real" players. We should also compare our qualitative results with quantitative statistical ones such as number and duration time of the playing session, payments done etc.

\section{ACKNOWLEDGEMENTS}

This research is conducted within the QuEJAnT project which brings together the LIRIS Laboratory and the video games companies Corexpert, Intellysurf and Kiniro. Funding for this project was provided by a grant from la Région Rhône Alpes and le Grand

\footnotetext{
${ }^{6}$ According to ISO 9241-210, user experience refers to "a person's perceptions and responses that result from the use or anticipated use of a product, system or service"
}

Lyon. The QuEJAnT project is labelled by the french competitiveness cluster Imaginove.

\section{REFERENCES}

Andersen, E., O'Rourke, E., Liu, Y.-E., Snider, R., Lowdermilk, J., Truong, D., Cooper, S., and Popovic, Z. (2012). The impact of tutorials on games of varying complexity. In Proceedings of the SIGCHI Conference on Human Factors in Computing Systems, CHI '12, pages 59-68, New York, NY, USA. ACM.

Bardram, J. E. (1997). Plans as situated action: an activity theory approach to workflow systems. In Proceedings of the fifth conference on European Conference on Computer-Supported Cooperative Work, ECSCW'97, pages 17-32. Kluwer Academic Publishers.

Bauckhage, C., Kersting, K., Sifa, R., Thurau, C., Drachen, A., and Canossa, A. (2012). How players lose interest in playing a game: An empirical study based on distributions of total playing times. In S. Lucas, S.-B. Cho, M. S. E., editor, Proceedings of the IEEE Conference on Computational Intelligence and Games (CIG), Granada, Spain.

Beal, C. R., Qu, L., and Lee, H. (2006). Classifying learner engagement through integration of multiple data sources. In Proceedings of the 21st national conference on Artificial intelligence - Volume 1, AAAI'06, pages 151-156. AAAI Press.

Boyle, E. A., Connolly, T. M., Hainey, T., and Boyle, J. M. (2012). Engagement in digital entertainment games: A systematic review. Computers in Human Behavior, 28(3):771-780.

Brien, H. L. O. and Toms, E. G. (2008). What is user engagement? a conceptual framework for defining user engagement with technology. Journal of the American Society for Information Science, 59(6):938-955.

Brockmyer, J. H., Fox, C. M., Curtiss, K. A., McBroom, E., Burkhart, K. M., and Pidruzny, J. N. (2009). The development of the game engagement questionnaire: A measure of engagement in video game-playing. Journal of Experimental Social Psychology, 45(4):624634.

Brown, E. and Cairns, P. (2004). A grounded investigation of game immersion. In $\mathrm{CHI}$ '04 extended abstracts on Human factors in computing systems, CHI EA '04, pages 1297-1300, New York, NY, USA. ACM.

Canossa, A. and Drachen, A. (2009). Patterns of play: Playpersonas in user-centred game development. In Barry, A., Helen, K., and Tanya, K., editors, Breaking New Ground: Innovation in Games, Play, Practice and Theory: Proceedings of the 2009 Digital Games Research Association Conference, London. Brunel University.

Champalle, O., Sehaba, K., Cosmas, D., Mille, A., and Prié, Y. (2012). Assistance to trainers for the observation and analysis activities of operators trainees on nuclear power plant full-scope simulator. In Xhafa, F., Barolli, L., Pop, F., 0001, X. C., and Cristea, V., editors, International Conference on Intelligent Networking and 
Collaborative Systems (INCoS 2012), pages 33-40. IEEE Computer Society.

Clauzel, D., Sehaba, K., and Prié, Y. (2011). Enhancing synchronous collaboration by using interactive visualisation of modelled traces. Simulation Modelling Practice and Theory, 19(1):84-97.

Cocea, M. and Weibelzahl, S. (2009). Log file analysis for disengagement detection in e-learning environments. User Modeling and User-Adapted Interaction, 19(4):341-385.

Coleridge, S. T. (1969). The collected works of Samuel Taylor Coleridge. Routledge and K. Paul ; Princeton University Press, [London] : [Princeton] :

Csikszentmihalyi, M. (1991). Flow: The Psychology of Optimal Experience. Harper Perennial.

de Aguilera, M. and Mendiz, A. (2003). Video games and education: (education in the face of a "parallel school"). Computers in Entertainment, 1(1):1-10.

Dietterich, T. G. (2002). Machine learning for sequential data: A review. In Proceedings of the Joint IAPR International Workshop on Structural, Syntactic, and Statistical Pattern Recognition, pages 15-30, London, UK. Springer-Verlag.

Dondlinger, M. J. (2007). Educational Video Game Design: A Review of the Literature. Journal of Applied Educational Technology, 4(1):21-31.

Egenfeldt-Nielsen, S. (2006). Overview of research on the educational use of video games. Digital Kompetanse, 1(3):184-213

Fredricks, J. A., Blumenfeld, P. C., and Paris, A. H. (2004). School Engagement: Potential of the Concept, State of the Evidence. Review of Educational Research, 74:59-109.

Fredricks, J. A. and McColskey, W. (2012). The measurement of student engagement: A comparative analysis of various methods and student self-report instruments. In Christenson, S. L., Reschly, A. L., and Wylie, C., editors, Handbook of Research on Student Engagement, pages 763-782. Springer US.

Gee, J. P. (2003). What video games have to teach us about learning and literacy. Computers in Entertainment, 1(1):20-20.

Greenhow, C., Robelia, B., and Hughes, J. E. (2009). Learning, Teaching, and Scholarship in a Digital Age: Web 2.0 and Classroom Research-What Path Should We Take "Now"? Educational Researcher, 38(4):246259.

Jennett, C., Cox, A. L., Cairns, P., Dhoparee, S., Epps, A., Tijs, T., and Walton, A. (2008). Measuring and defining the experience of immersion in games. International Journal of Human-Computer Studies, 66(9):641-661.

Kaptelinin, V. (2005). The object of activity: Making sense of the sense-maker. Mind, Culture, and Activity, 12(1):4-18.

Kaptelinin, V. and Nardi, B. A. (2006). Acting with Technology: Activity Theory and Interaction Design. The MIT Press.

Kivikangas, J. M., Chanel, G., Cowley, B., Ekman, I., Salminen, M., Jrvel, S., and Ravaja, N. (2011). A review of the use of psychophysiological methods in game research. Journal of Gaming and Virtual Worlds, 3(3):181-199.

Köck, M. and Paramythis, A. (2011). Activity sequence modelling and dynamic clustering for personalized elearning. User Modeling and User-Adapted Interaction, 21(1-2):51-97.

Lazzaro, N. (2004). Why We Play Games: Four Keys to More Emotion Without Story. In Game Developers Conference.

Leontiev, A. N. (1978). Activity, consciousness and personality. Prentice Hall, Englewood Cliffs, NJ.

Prensky, M. (2007). Digital Game-Based Learning. Paragon House.

Przybylski, A. K., Rigby, C. S., and Ryan, R. M. (2010). A motivational model of video game engagement. Review of General Psychology, 14(2):154-166.

Reeve, J., Jang, H., Carrell, D., Jeon, S., and Barch, J. (2004). Enhancing students' engagement by increasing teachers' autonomy support. Motivation and Emotion, 28:147-169.

Reschly, A. L. and Christenson, S. L. (2006). Research leading to a predictive model of dropout and completion among students with mild disabilities and the role of student engagement. Remedial and Special Education, 27:276-292.

Romero, C. and Ventura, S. (2010). Educational data mining: a review of the state of the art. Transactions on Systems, Man, and Cybernetics-Part C: Applications and Reviews, 40(6):601-618.

Ryan, R. M. and Deci, E. L. (2000). Self-determination theory and the facilitation of intrinsic motivation, social development, and well-being. The American psychologist, 55:68-78.

Settouti, L. S., Prié, Y., Marty, J.-C., and Mille, A. (2009) A trace-based system for technology-enhanced learning systems personalisation. In Proceedings of the 2009 Ninth IEEE International Conference on Advanced Learning Technologies, ICALT '09, pages 9397, Washington, DC, USA. IEEE Computer Society.

Skinner, E. A. and Belmont, M. J. (1993). Motivation in the classroom: Reciprocal effects of teacher behavior and student engagement across the school year. Journal of Educational Psychology, 85(4):571-581.

Tamborini, R. and Skalski, P. (2006). The role of presence in the experience of electronic games. In Vorderer, $\mathrm{P}$. and Bryant, J., editors, Playing video games - motives, responses, and consequences, pages 225-240. Lawrence Erlbaum.

Vygotsky, L. (1978). Mind in Society: The Development of Higher Psychological Processes. Harvard University Press, Cambridge, MA.

Weber, B. G., Mateas, M., and Jhala, A. (2011). Using data mining to model player experience. In FDG Workshop on Evaluating Player Experience in Games, Bordeaux, France. ACM, ACM

Yee, N. (2006). Motivations for play in online games. $C y$ berpsychology and Behavior, 9(6):772-775. 